\title{
Zinc oxide tape: a useful dressing for the recalcitrant finger-tip and soft-tissue injury
}

\author{
G. HUGHES ${ }^{1} \&$ N. R. McLEAN ${ }^{2}$
}

${ }^{1}$ Department of Accident and Emergency, Charing Cross Hospital, and ${ }^{2}$ Department of Plastic, Reconstructive and Burns Surgery, Queen Mary's Hospital, Roehampton, London, England

\section{SUMMARY}

Zinc oxide tape has been used successfully in $\mathbf{4 0}$ patients to treat finger-tip and softtissue injuries which had not healed with conventional dressings. It is easy to apply, cheap and readily accepted by both patients and staff. The authors strongly recommend this simple dressing for the slow-to-heal finger-tip injury.

\section{INTRODUCTION}

Elemental zinc is important in wound healing (Hallbrook \& Lanner, 1972; Hallmanns, 1977a; Pories et al., 1967) and, indeed, there is evidence that re-epithelialization may be delayed by zinc deficiency (Standstead et al., 1970; Oberleas et al., 1971; Larson et al., 1970). In 1977, Hallmanns showed that this effect can be reversed by use of zinc-based adhesive dressing. Pories et al., (1967) have commented that oral zinc sulphate, supplementary to a 'normal' diet in healthy military personnel, accelerated wound healing when compared to controls. Zinc (in the form of a semi-adhesive tape) has also been found to be extremely useful in the treatment of burns (Hallmanns, 1977b).

This paper reports the use of zinc oxide tape in the management of soft-tissue wounds, particularly the slow-to-heal finger-tip injury which has not responded to long-term treatment with conventional dressings.

Correspondence: G. Hughes, Department of Accident and Emergency, Charing Cross Hospital, London W6 8RF, England. 


\section{SUBJECTS AND METHODS}

The 40 patients in this study initially presented to the accident and emergency (A\&E) department with a soft-tissue injury. Primary treatment consisted of thorough wound toilet and the application of vaseline gauze dressings (or in some cases a Meloling dressing). Tetanus immunization and antibiotics were given as appropriate.

In all 40 patients studied, the wounds were slow to heal and they were referred to the plastic surgery dressings clinic. There, the wounds were cleaned, inspected and zinc ${ }^{2}$ oxide tape applied directly to the wound as the only dressing (Fig. 1).

Patients were instructed to apply the tape to the wound daily, or more frequentlyo should it become soiled or loosen. They were advised that there might be a short period $\vec{\omega}$ of increased wound discharge, necessitating more frequent change of the dressing. This normally settled by $3-5$ days.

Zinc oxide tape is composed of a lotion web foundation with a composite mixture of gum, resin and zinc oxide paste, presented as $1.25-\mathrm{cm}$ and $2.5-\mathrm{cm}$ diameter rolls each 10 t $\mathrm{m}$ in length. (Fig. 2). Each patient was given a roll of tape and dressed the woundsw themselves.

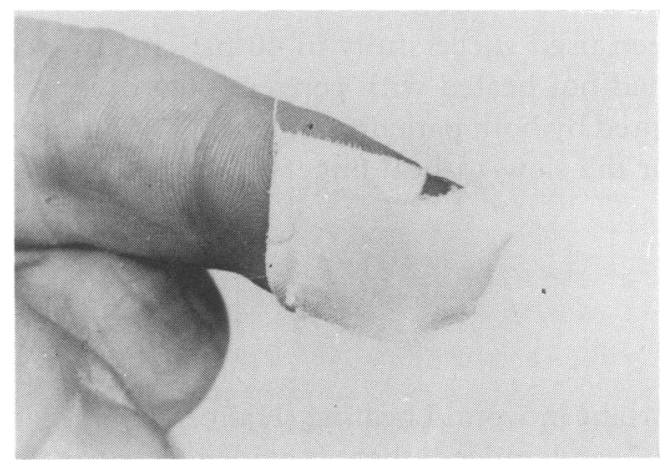

Fig. 1 Zinc oxide tape applied directly to a finger-tip wound as the only dressing.

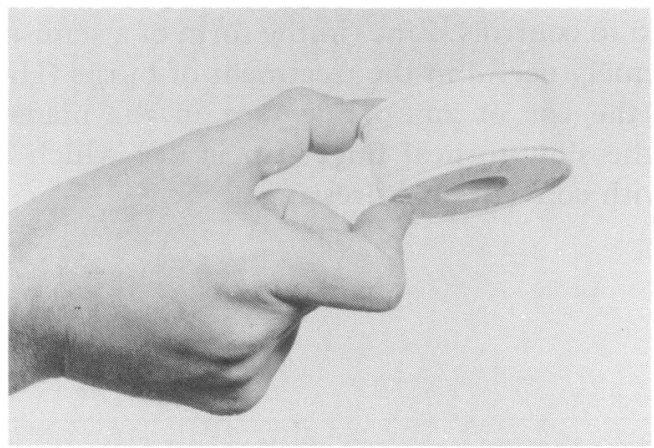

Fig. 2 A $2 \cdot 25-\mathrm{cm}$ diameter roll of zinc oxide tape, $10 \mathrm{~m}$ in length. 


\section{RESULTS}

Forty patients were studied, of whom two-thirds were male. The majority were treated for 2-3 weeks prior to the application of zinc tape, although one case was not referred for nearly 3 months. Time to wound healing afer tape application varied from 7-40 days with a median of 10 days (Table 1 ).

Table 1 Summary of patients

\begin{tabular}{llll}
\hline $\begin{array}{l}\text { No. of patients } \\
\text { Median age (years) }\end{array}$ & 40 & (Male: 27; & female: 13) \\
$\begin{array}{l}\text { Median days to referral } \\
\text { to Dressing Clinic }\end{array}$ & 25 (range 14-68) & \\
$\begin{array}{l}\text { Median days to healing } \\
\text { with zinc tape }\end{array}$ & 17 & \\
\hline
\end{tabular}

Thirty-two patients presented with hand wounds, the majority of the remainder being on the lower limb (Fig. $3 \& 4$ ).

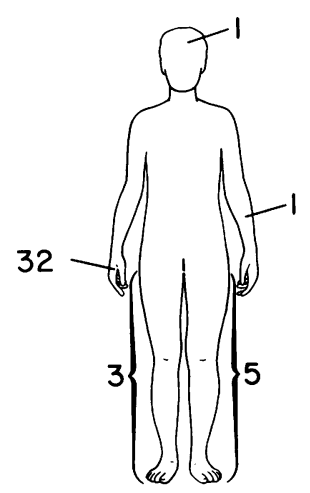

Fig. 3 Site of injuries (figures refer to incidence of injury to each area).

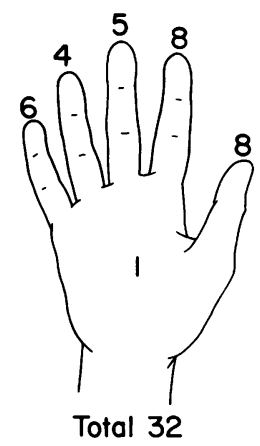

Fig. 4 Injuries to the hand (figures refer to the incidence of injuries to each digit). 
Table 2 Causes of injury (total 40)

\begin{tabular}{lr}
\hline Crush injury & 12 \\
Laceration & 9 \\
Saw injury & 7 \\
Fall with skin loss & 4 \\
Burn & 4 \\
Penetrating F.B. with skin loss & 2 \\
Infected insect bite & 1 \\
Delayed healing after minor op & 1 \\
\hline
\end{tabular}

Causes of injury are shown in Table 2, the commonest being a crushing injury, $\overrightarrow{\vec{\omega}}$ closely followed by a laceration.

All wounds healed without complications and, in every case, the treatment was $\frac{\mathbb{D}}{3}$. painfree, the dressing easy to manage and all patients were completely satisfied with the $e_{+}^{G}$ zinc oxide tape.

\section{DISCUSSION}

Zinc-based dressings have been used in treating venous leg ulcers (Hallbrook \& Lanner, 1972) and burns (Hallmanns, 1977b) where it was absorbed into the granulation tissug. $\vec{\bullet}$ Oral zinc sulphate has been given in the treatment of ischaemic leg ulcers (Haegar $\$ \infty$ Lanner, 1974) as well as in healthy individuals with surgical wounds (Pories et a蛋, 1967).

Zinc is absorbed from the tape into pancreas, bone, hair and skin in rats (Hallmanns, 1977a) and it probably acts at the wound site where it is incorporated into enzyme systems involved in protein synthesis and cellular metabolism (i.e. it is an important cofactor in wound healing and tissue repair).

Zinc tape has been used in our unit for several years for managing burns in areas which are small and difficult to heal, particularly under pressure garments where they? rub over joint surfaces.

All patients in this study had simple wounds which had not responded to treatment by conventional dressing. The majority were finger-tip injuries, which healed by 3 . secondary intention under the zinc tape. As healing occurs in the moist environment under the tape, there is a short period of increased wound discharge. Because the tape is 3 non adherant, it can easily be removed to allow for cleaning of this discharge ando inspection of the wound. Most of our patients quickly returned to work with the zinc dressing in place. As many were manual workers, the tape frequently became soiled but as they carried their roll of tape with them it was a simple matter to change the dressingo as needed.

Whilst it is not our policy to use daily dressing when conventional treatment of the acutely injured finger tip is being followed, zinc tape is such an easy dressing to apply that the patients often change it themselves so as to have a 'clean' dressing in place.

The initial management of these wounds was vaseline gauze under a dry dressing. This requires several visits to hospital for re-dressing and wound inspection, a process 
which may be painful, particularly in the young child. Some departments use a melolin type dressing, but in the authors' experience it tends to adhere to wet wounds and may be extremely uncomfortable to remove.

In a 12-month period at Charing Cross Hospital, approximately 1500 patients were treated for finger-tip injuries. Those with recalcitrant wounds (amounting to only a small percentage of the total) are an extremely difficult group to manage as the unhealed wound often prevents the patient returning to manual work.

The advantages of zinc tape are:

(1) It is cheap. The $1 \cdot 25-\mathrm{cm}$ roll costs $36 \mathrm{p}$ (only part of which is used on each patient). Compare this to vaseline gauze $(10 \times 10 \mathrm{~cm})$ which costs $10 \cdot 1 \mathrm{p}$ each, antibioticimpregnated vaseline gauze $(10 \times 10 \mathrm{~cm})$ at $26.5 \mathrm{p}$ each and Melolin $(10 \times 10 \mathrm{~cm})$ at $11 \mathrm{p}$ each.

(2) It is easily applied and understood by both patient and parent.

(3) Convenience: it reduces the number of hospital attendances.

(4) It is non-bulky and, therefore, does not interfere with hand function, allowing early return to work, though it provides cover and protection of the healing wound.

(5) It is atraumatic to the wound and painless to remove.

Further studies are underway in this department to investigate its use earlier in the treatment of soft tissue wounds, and to compare it with other more conventional dressings used initially in the $A \& E$ department. In conclusion, the authors would strongly recommend the use of zinc oxide tape in simple uncomplicated wounds which would be expected to heal by secondary intention. It should be used after initial haemorrhage and oedema have subsided.

\section{REFERENCES}

Haeger K. \& Lanner E. (1974) Oral zinc sulphate and ischaemic leg ulcers $V A S A$ 3, 77.

Hallbrook I. T. \& Lanner E. (1972) Serum zinc and healing of venous leg ulcers. Lancet ii, 780-2.

Hallmanns G. (1977a) Zinc resorption from zinc tape during wound healing, an experimental study in the rat. Scandinavian fournal of Plastic and Reconstructive Surgery 11, 27-32.

Hallmanns G. (1977b) Treatment of burns with zinc tape. Scandinavian fournal of Plastic and Reconstructive Surgery 11, 155-61.

Larson D. L., Maxwell R., Abston S. \& Dobrkovsky M. (1970) Zinc deficiency in burned children. Plastic and Reconstructive Surgery 46, 13-21.

Oberleas D., Seymour J. K., Lenaghan R., Hovanesian J., Wilson R. F. \& Prasad A. S. (1971) Effect of zinc deficiency on wound healing in rats. American fournal of Surgery 121, 566-8.

Pories W. J., Menzel J. H., Rob G. C. \& Strain W. H. (1967) Acceleration of healing with zinc sulphate. Annals of Surgery 165, 432-6.

Sandstead H. H., Lanier U. C., Shepard G. H. \& Gillespie D. D. (1970) Zinc and wound healing: effects of zinc deficiency and zinc supplementation. American fournal of Clinical Nutrition 23, 514-19. 